Tohoku J. Exp. Med., 2003, 201, 147-155

\title{
Thiols, Malonaldehyde and Total Antioxidant Status in the Turkish Patients with Type 2 Diabetes Mellitus
}

\author{
Belgin Süsleyici Duman, Melek ÖZtürk, ${ }^{1}$ Selma Yilmazer ${ }^{1}$ and Hüsrev \\ HATEMi ${ }^{2,3}$ \\ Department of Medical Biology and Genetics, Kadir Has University Faculty of \\ Medicine, Istanbul, Turkey, \\ ${ }^{1}$ Department of Medical Biology, Istanbul University Cerrahpasa Faculty of \\ Medicine, Istanbul, Turkey, \\ ${ }^{2}$ Turkish Diabetes Hospital, Istanbul, Turkey, and \\ ${ }^{3}$ Department of Endocrinology and Metabolism, Istanbul University, Cerrahpasa \\ Faculty of Medicine, Istanbul, Turkey
}

Duman, B.S., Öztürk, M., Yilmazer, S. and Hatemi, H. Thiols, Malonaldehyde and Total Antioxidant Status in the Turkish Patients with Type 2 Diabetes Mellitus. Tohoku J. Exp. Med., 2003, 201 (3), 147-155— Non-insulin-dependent (Type 2) diabetes mellitus (NIDDM) is a risk factor for cardiovascular diseases (CVD). Oxidative stress mechanisms are often reported to be implied in type 2 diabetes mellitus. In order to determine their clinical relevance, we investigated several plasma indicators in the Turkish patients with NIDDM: (i) homocysteine (Hcy) and cysteine (Cys) which contribute to increase the risk of atherosclerosis during NIDDM, (ii) glutathione (GSH) and cysteinylglycine (CysGly) resulting from GSH degradation catalyzed by $\boldsymbol{\gamma}$-glutamylcysteine transferase (GGT), (iii) malonaldehyde (MDA) as a marker for lipid peroxidation, and (iv) total antioxidant status (TAS). Our main results were evaluated based on sex and diabetic status. In female patients, plasma concentrations of MDA and Hcy were significantly higher than in controls, while GSH levels were significantly lower. In males, a difference between control and diabetic groups was noticed only for Hcy, levels being also higher in patients. In the diabetic group, increase in serum glucose concentration was significantly correlated with increased GGT activity. In both controls and diabetic patients, GGT activity was correlated with a raised Cys concentration and a decreased GSH level. In both controls and diabetic patients, there were significant positive correlations between Cys and Hcy and between GSH and Hcy. We concluded that GSH and MDA levels are clinical indicators for an oxidative process linked to type 2 diabetes mellitus, especially in women. NIDDM; oxidative stress; lipid peroxidation; sex (C) 2003 Tohoku University Medical Press

Received May 26, 2003; revision accepted for publication September 25, 2003.

Address for reprints: Dr. Belgin Süsleyici Duman, Department of Medical Biology and Genetics,

Kadir Has University Faculty of Medicine, Vefabey Street, No:5 80810, Gayrettepe-Istanbul, Turkey.

e-mail: bsusleyici@ khas.edu.tr 
One of the principal causes of morbidity and mortality in the individuals with diabetes mellitus is atherosclerosis and resulting cardiovascular diseases (CVD) (Boemi et al. 1993). Type 2 diabetes mellitus with an increasing incidence world wide is characterized by an increased risk for the development of neuropathic, micro- and macro-vascular complications (Assmann et al. 1999). Several experimental, epidemiologic and clinical studies support the notion that oxidative stress plays a significant role in type 2 diabetes mellitus (De Zwart et al. 1999) and in the development of CVD (Jacob and Burri 1996; Garewal 1997).

The plasma thiols measurement appears to be a suitable parameter to investigate the numerous pathological diseases that are related to oxidative stress processes. Hyperhomocysteinemia has been suggested to promote the production of hydroxyl radicals, lipid peroxidation initiators, through homocysteine (Hcy) autooxidation and thiolactone formation (Stamler et al. 1993). Moreover, Hcy represents a strong and independent risk factor for CVD (Ueland et al. 1992; Boushey et al. 1995; Graham et al. 1997). The incidence of CVD increases with increasing plasma or serum Hcy concentrations (Ueland et al. 1992; Boushey et al. 1995). Furthermore, hyperhomocysteinemia has been described in diabetic patients (Munshi et al. 1996; Hoogeveen et al. 1998). Though less reactive than Hcy, cysteine (Cys) exhibits some of its chemical properties through the sulfhydryl group (Stamper and Slivka 1996). The potential noxious effects of Cys may have been overlooked since few studies analysed the relationship between Cys and CVD (Araki et al. 1989; Mansoor et al. 1995; Verhoef et al. 1996). GSH plays an important role as a scavenger of oxidant species and free radicals (Meister and Tate 1976). The precursors involved into GSH biosynthesis, i.e. Cys and $\gamma$-glutamylcysteine ( $\gamma$-GluCys), and cysteinylglycine (CysGly) resulting from the reaction catalysed by $\gamma$ glutamyltransferase (GGT E.C.2.3.2.2), are also of interest to evaluate the GSH homeostasis in the biological system, e.g., cells, tissues, blood or plasma (Stamler and Slivka 1996). Moreover, CysGly is a highly reactive metabolite and can produce reactive oxygen species (ROS) in presence of transition metals (Pompella 1997; Droz$\mathrm{d} z$ et al. 1998) thereby leading to lipid peroxidation (LPO). Serum $\gamma$-glutamylcysteine transferase (GGT) is directly involved in GSH metabolism and also modulates Cys and CysGly levels. Perry et al. (1998) suggested that an increased serum GGT level is an independent risk factor for CVD in NIDDM. Serum GGT level might be a simple and reliable marker of hepatic insulin resistance.

In the same way, the capacity of a subject to resist oxidative stress is indicated by the total antioxidant status (TAS) (Miller et al. 1993; Maxwell et al. 1997). In serum, several antioxidant compounds contribute to TAS mainly albumin, uric acid, $\alpha$-tocopherol, ascorbic acid and bilirubin (Cao and Prior 1998; Diaz et al. 1998).

Determination of GSH, MDA (as a free radical-mediated LPO product) and TAS is therefore of practical and clinical importance in order to assess the implication of free radicals in type 2 diabetes. In the present study involving Turkish subjects, the main objective was to determine whether there was a link between clinical parameters and (i) the status of thiols and GGT activity in type 2 diabetes, (ii) the increase of free radical activity, measured as MDA, and (iii) the TAS in diabetic and healthy subjects.

\section{Materials AND Methods}

\section{Subjects}

Patients with type 2 diabetes mellitus (52 men and 55 women) were enrolled. All patients were taking oral antidiabetic drugs. The diagnosis of type 2 diabetes mellitus was based on the criteria of The Expert Committee on the diagnosis of diabetes mellitus (2000). Diabetic patients were recruited from those consecutive- 
ly attending the Turkish Diabetes Hospital, Istanbul for their routine clinical examination (every 1-2 months) and included in the study, in agreement with Turkish local ethic committee. Non diabetic control subjects were recruited from those attending their routine health screening in the Central Laboratory of Cerrahpasa Medical Faculty (Istanbul University, Turkey). As controls, 99 healthy subjects (46 men and 53 women) were studied. No patients in the study were related. All diabetic patients had normal hepatic and endocrine functions and were relatively well controlled with glycosylated hemoglobin $\left(\mathrm{HbA}_{1 \mathrm{c}}\right) \leqq 6-7 \%$ (normal range $\leqq 8 \%$ ). Tobacco and alcohol consumptions were collected by using standardised questionnaire. The patients with macro- and microangiopathic complications were excluded from this study. Determination of baseline cardiovascular risk factors included age, body mass index (BMI) (Angelico et al. 1990), alcohol consumption and smoking status.

\section{Blood sampling}

After an overnight fast, blood was drawn by venipuncture at the antecubital vein from the subjects between 8:00 and 10:00 a.m. The samples were collected in two vacuum tubes: one tube with EDTA, one tube without anticoagulant. Blood was centrifuged promptly at $1000 \mathrm{~g}$ for 15 minutes at $+4 \mathrm{C}$ for plasma and serum.

\section{Assays of biochemical parameters}

Total cholesterol (TC), triglyceride (TG) and glucose were measured in serum on a Cobas-Mira analyzer (Roche Diagnostics, Meylan, France). Serum were analysed without preteatment and diluted in double-distilled water when lipid levels exceeded reference values. Inter-assay coefficients of variation of this method were $4.7 \%, 2.1 \%$ and $1.0 \%$, for TG, TC and glucose, respectively. Blood glucose values were measured from venous blood serum.

GGT activity was measured in plasma samples using a spectrophotocolorimetric assay kit (Granutest25 ${ }^{\circledR}$, Merck) on a Cobas-Mira analyser. Intra- and inter-assay coefficients of variations were $2.0 \%$ and $2.4 \%$, respectively.

Serum TAS was determined on a Cobas-Fara analyser (Roche Diagnostics) with a “Total Antioxidant Status ${ }^{\circledR ”}$ kit (Randox Labs., Crumlin, UK). The assay principle relies upon the ability of antioxidants within biological fluids to quench the absorbance (measured at $600 \mathrm{~nm}$ ) of the radical cation formed by the reaction of a chromogen (2,2'-azino-di-[ethylbenzthiazoline sulfonate]; $\mathrm{ABTS}^{\circledR}$ ) with a peroxidase and $\mathrm{H}_{2} \mathrm{O}_{2}$ (Miller et al. 1993). The system calibrator is $\operatorname{Trolox}^{\circledR}$, a water-soluble vitamine $\mathrm{E}$ analogue. Results are expressed as $\mu \mathrm{mol}$ Trolox/1. Intra- and inter-assay coefficients of variations were $1.9 \%$ and $3.5 \%$, respectively.

Total plasma low molecular mass thiols (all forms including disulfides, mixed disulfides, and free thiols), i.e. Cys, CysGly, Hcy and GSH, were measured simultaneously using a high-performance liquid chromatography (HPLC) method including a precolumn derivatization (with 7-fluoro-2, 1, 3-benzoxadiazole-4sulfonamide; ABD-F) and fluorescence detection (Salazar et al. 1999). Intra- and inter-assay coefficients of variations measured with a plasma pool was $2.2 \%$ and $7.2 \%$ for Cys, $1.7 \%$ and $3.1 \%$ for CysGly, $1.9 \%$ and $4.2 \%$ for Hcy and $7.2 \%$ and $10 \%$ for GSH at concentrations of 178.0, 27.8, 7.9 and $3.4 \mu \mathrm{mol} /$ liter, respectively.

The HPLC method for plasma MDA measurements (Young and Trimble 1991) consists in the following steps: (i) precipitation of proteins by phosphoric acid in order to eliminate the interference by the water-soluble substances that react with the thiobarbituric acid (TBA), (ii) formation of the TBA-MDA adduct and (iii) separation in a HPLC system with fluorescence detection. Intra- and inter-assay coefficients of variations were $5.1 \%$ and $10.5 \%$, respectively. 


\section{Statistical analysis}

Statistical analyses were performed using the BMDP $^{\circledR}$ statistical software (UCLA, Los Angeles, CA, USA). Values were expressed as mean \pm S.D. Comparison between groups was performed using Student t-test or ANOVA. Ascendant stepwise multiple regression was performed to analyze interrelationships between parameters of interest (thiols, MDA and TAS levels) and the following factors: age, sex, BMI, tobacco consumption, alcohol consumption, serum cholesterol, triglycerides, apo AI, apo B and glucose concentration, $\mathrm{HbA}_{1 \mathrm{c}}$ level, and GGT activity. Statistical significance for all tests was accepted at $p \leqq 0.05$ level.

\section{RESULTS}

The main characteristics of controls and patients are shown in Table 1. In females, patients with NIDDM had higher TC, apo B and lower apo A1 concentrations than controls, difference for apo A1 level being only borderline significant. In males, characteristics did not differ significantly, except for glucose, between controls and patients. In female patients, plasma concentrations of MDA and Hcy were significantly higher than in controls, while GSH levels were significantly lower. In males, a difference between diabetic and control groups was noticed only for Hcy, levels being higher in type 2 diabetics.

The association between oxidative stress indicators and their clinical or biological determinants is shown in Table 2. Glucose concentration, describing the diabetic status, is significantly correlated with a reduced serum TAS. Even without significant difference of GGT

TABLE 1. Main characteristics, TAS, and, concentrations of MDA and thiol in controls $(n=$ 99) and type 2 diabetic patients $(n=107)^{a}$

\begin{tabular}{|c|c|c|c|c|}
\hline & \multicolumn{2}{|c|}{ Men } & \multicolumn{2}{|c|}{ Women } \\
\hline & $\begin{array}{l}\text { Control } \\
(n=46)\end{array}$ & $\begin{array}{c}\text { Diabetes } \\
(n=52)\end{array}$ & $\begin{array}{l}\text { Control } \\
(n=53)\end{array}$ & $\begin{array}{c}\text { Diabetes } \\
(n=55)\end{array}$ \\
\hline Age (years) & $55.9 \pm 14.5$ & $57.8 \pm 11.8$ & $55.2 \pm 9.1$ & $57.9 \pm 8.25$ \\
\hline Body mass index $\left(\mathrm{kg} / \mathrm{m}^{2}\right)$ & $21.6 \pm 3.2$ & $21.8 \pm 3.1$ & $23.4 \pm 3.5$ & $23.8 \pm 3.9$ \\
\hline Smoking (pack-year) & $1.9 \pm 1.2$ & $2.1 \pm 0.9$ & $1.1 \pm 0.8$ & $0.9 \pm 0.7$ \\
\hline Alcohol (g/week) & $0.07 \pm 0.26$ & $0.02 \pm 0.15$ & - & - \\
\hline Serum glucose (mmol/liter) & $3.35 \pm 0.56$ & $9.07 \pm 3.83^{* * *}$ & $3.54 \pm 0.52$ & $9.08 \pm 3.80^{* * *}$ \\
\hline $\mathrm{HbA}_{1 \mathrm{c}}(\%)$ & ND & $6.7 \pm 1.9$ & ND & $6.9 \pm 2.2$ \\
\hline Serum triglycerides $(\mathrm{mmol} / \mathrm{liter})^{\mathrm{b}}$ & $1.48 \pm 0.55$ & $2.18 \pm 2.12$ & $1.65 \pm 0.67$ & $1.70 \pm 0.95$ \\
\hline Serum cholesterol (mmol/liter) & $4.89 \pm 1.46$ & $5.17 \pm 1.05$ & $5.30 \pm 1.10$ & $5.86 \pm 1.04^{*}$ \\
\hline Apo A1 (g/liter) & $1.28 \pm 0.25$ & $1.27 \pm 0.24$ & $1.54 \pm 0.29$ & $1.44 \pm 0.22$ \\
\hline Apo B (g/liter) & $1.11 \pm 0.26$ & $1.11 \pm 0.31$ & $1.07 \pm 0.25$ & $1.18 \pm 0.25^{*}$ \\
\hline GGT activity $(\mathrm{U} / \text { liter })^{\mathrm{b}}$ & $20.9 \pm 2.8$ & $25.0 \pm 3.1$ & $20.0 \pm 1.7$ & $21.9 \pm 2.4$ \\
\hline MDA ( $\mu$ mol/liter) & $0.36 \pm 0.15$ & $0.43 \pm 0.19$ & $0.37 \pm 0.12$ & $0.47 \pm 0.23^{* *}$ \\
\hline TAS ( $\mu$ mol/1 equiv Trolox $\left.{ }^{\circledR}\right)$ & $1.40 \pm 0.12$ & $1.43 \pm 0.14$ & $1.39 \pm 0.14$ & $1.42 \pm 0.12$ \\
\hline Plasma cysteine ( $\mu \mathrm{mol} /$ liter $)$ & $279 \pm 42$ & $291 \pm 53$ & $269 \pm 57$ & $282 \pm 57$ \\
\hline Plasma cysteinylglycine ( $\mu \mathrm{mol} /$ liter $)$ & $41.1 \pm 7.7$ & $40.6 \pm 13.5$ & $37.0 \pm 8.3$ & $37.9 \pm 10.8$ \\
\hline Plasma homocysteine ( $\mu \mathrm{mol} /$ liter $)$ & $11.2 \pm 3.6$ & $14.6 \pm 5.7^{*}$ & $9.4 \pm 2.7$ & $11.4 \pm 3.7^{* *}$ \\
\hline Plasma glutathione ( $\mu \mathrm{mol} /$ liter) & $7.7 \pm 2.1$ & $7.3 \pm 3.1$ & $7.8 \pm 2.7$ & $6.4 \pm 3.4^{*}$ \\
\hline
\end{tabular}

${ }^{a}$ Values are means \pm S.D.

${ }^{\mathrm{b}}$ Test on log-transformed values.

${ }^{*} p \leqq 0.05, * * p \leqq 0.01,{ }^{* * *} p \leqq 0.001$ : Student's $t$-test between controls and patients or $\chi^{2}$ test ND, not determined. 
TABLE 2. Determinants of TAS, MDA and thiol levels in (A) controls $(n=99)$ and (B) type 2 diabetic patients $(n=107)$ (both males and females) ${ }^{a}$

A (Controls)

\begin{tabular}{lcccccc}
\hline & $\begin{array}{c}\text { TAS } \\
(\mu \mathrm{mol} / \mathrm{l})\end{array}$ & $\begin{array}{c}\text { MDA } \\
(\mu \mathrm{mol} / \mathrm{l})\end{array}$ & $\begin{array}{c}\text { Cys } \\
(\mu \mathrm{mol} / \mathrm{l})\end{array}$ & $\begin{array}{c}\text { CysGly } \\
(\mu \mathrm{mol} / \mathrm{l})\end{array}$ & $\begin{array}{c}\text { Hcy } \\
(\mu \mathrm{mol} / \mathrm{l})\end{array}$ & $\begin{array}{c}\text { GSH } \\
(\mu \mathrm{mol} / \mathrm{l})\end{array}$ \\
\hline Age (years) & - & - & $1.27(0.49)^{* *}$ & - & - & $0.067(0.028)^{*}$ \\
Sex & - & - & - & - & $-3.11(1.16)^{* *}$ & - \\
BMI $\left(\mathrm{kg} / \mathrm{m}^{2}\right)$ & - & - & - & - & - & - \\
$\begin{array}{l}\text { Serum cholesterol } \\
(\mathrm{mmol} / \mathrm{l})\end{array}$ & - & - & $14.5(4.9)^{* *}$ & - & - & - \\
GGT activity $(\mathrm{U} / \mathrm{l})^{\mathrm{b}}$ & - & - & $47.9(22.8)^{*}$ & - & - & $-2.67(1.25)^{*}$ \\
Intercept & - & - & 70.8 & - & 17.66 & 7.72 \\
$\mathrm{R}^{2}$ & - & - & 0.238 & - & 0.095 & 0.161 \\
\hline
\end{tabular}

$B$ (Diabetic patients)

\begin{tabular}{lcccccc}
\hline & $\begin{array}{c}\text { TAS } \\
(\mu \mathrm{mol} / \mathrm{l})\end{array}$ & $\begin{array}{c}\text { MDA } \\
(\mu \mathrm{mol} / \mathrm{l})\end{array}$ & $\begin{array}{c}\text { Cys } \\
(\mu \mathrm{mol} / \mathrm{l})\end{array}$ & $\begin{array}{c}\text { CysGly } \\
(\mu \mathrm{mol} / \mathrm{l})\end{array}$ & $\begin{array}{c}\text { Hcy } \\
(\mu \mathrm{mol} / \mathrm{l})\end{array}$ & $\begin{array}{c}\mathrm{GSH} \\
(\mu \mathrm{mol} / \mathrm{l})\end{array}$ \\
\hline Age (years) & - & - & $2.54(0.62)^{* * *}$ & - & $0.134(0.036)^{* * *}$ & - \\
Sex & - & - & - & - & $-2.13(0.68)^{* *}$ & - \\
BMI $\left(\mathrm{kg} / \mathrm{m}^{2}\right)$ & - & $0.015(0.006)^{*}$ & - & - & - & - \\
$\begin{array}{l}\text { Serum glucose } \\
(\mathrm{mmol} / \mathrm{l})\end{array}$ & $0.0093(0.0036)^{* *}$ & - & - & - & - & - \\
GGT activity $(\mathrm{U} / \mathrm{l})^{\mathrm{b}}$ & $0.178(0.053)^{* * *}$ & - & $60.6(21.8)^{* *}$ & - & - & $4.61(1.31)^{* * *}$ \\
Intercept & 1.28 & 0.876 & 56.4 & - & 5.60 & 12.66 \\
$\mathrm{R}^{2}$ & 0.175 & 0.077 & 0.243 & - & 0.224 & 0.134 \\
\hline
\end{tabular}

${ }^{a}$ Regression coefficient (standard error).

${ }^{\mathrm{b}} \mathrm{Log}$-transformed values.

NS not significant, ${ }^{*} p \leqq 0.05,{ }^{* *} p \leqq 0.01,{ }^{* * *} p \leqq 0.001$.

TAS, Total antioxidant status; MDA, Malonaldehyde; GSH, Glutathione.

activity between the control and diabetic groups, in both controls and diabetic patients GGT activity is related with a raised Cys concentration and a decreased GSH level. Nevertheless, no potential activity of GGT on GSH was detected after the blood uptake: GSH concentration did not change during sample treatment in the range of GGT activities met in the present study (data not shown).

The relationships between oxidative stress indicators are summarized in Table 3 . In both controls and diabetic patients, there are significant positive correlations between Cys and Hcy and between GSH and Hcy.

\section{DISCUSSION}

Patients with NIDDM have increased mortality and morbidity compared with nondiabetics and are more likely to develop CVD (Boemi et al. 1993). The high risk for vascular disease can only partly be explained by the traditional risk factors for the general population such as smoking, hypertension and raised cholesterol. It has been proposed that oxidative stress may be associated with the pathogenesis of the complications of NIDDM (De Zwart et al. 1999), particularly CVD (Jacob and Burri 1996; Garewal 1997).

One issue that has not previously been addressed is the interrelationship between thiols 
TABle 3. Correlation coefficients between TAS, MDA

and thiol levels in $(A)$ controls $(n=99)$ and

(B) type 2 diabetic patients $(n=107)$ (both

males and females) adjusted for age and sex

\begin{tabular}{lccccc}
\multicolumn{2}{c}{$A$ (Controls) } \\
\hline & TAS & MDA & Cys & CysGly & Hcy \\
\hline MDA & -0.012 & - & - & - & - \\
Cys & -0.185 & 0.034 & - & - & - \\
CysGly & $0.241^{\mathrm{b}}$ & 0.143 & $0.350^{\mathrm{c}}$ & - & - \\
Hcy & 0.152 & -0.143 & $0.332^{\mathrm{c}}$ & $0.272^{\mathrm{b}}$ & - \\
GSH & 0.085 & -0.156 & 0.027 & 0.157 & $0.298^{\mathrm{b}}$ \\
\hline
\end{tabular}

\begin{tabular}{lccccc}
\multicolumn{7}{c}{ (Diabetic patients) } \\
\hline \multicolumn{7}{c}{ TAS } & MDA & Cys & CysGly & Hcy \\
\hline MDA & -0.004 & - & - & - & - \\
Cys & 0.108 & 0.078 & - & - & - \\
CysGly & $0.258^{\mathrm{b}}$ & 0.159 & -0.101 & - & - \\
Hcy & $0.293^{\mathrm{b}}$ & 0.171 & $0.275^{\mathrm{b}}$ & $0.431^{\mathrm{d}}$ & - \\
GSH & $-0.201^{\mathrm{a}}$ & 0.092 & $-0.266^{\mathrm{b}}$ & $0.531^{\mathrm{d}}$ & $0.291^{\mathrm{b}}$ \\
\hline \multicolumn{5}{c}{$\mathrm{a} p \leqq 0.10,{ }^{\mathrm{b}} p \leqq 0.05,{ }^{\mathrm{c}} p \leqq 0.01,{ }^{\mathrm{d}} p \leqq 0.001$}
\end{tabular}

(i.e., Cys, CysGly, Hcy and GSH) status and type 2 diabetes. According to a previous study (Chico et al. 1998), diabetic patients had higher Hcy levels than control subjects. Moreover, the observed sex-related difference (Hcy concentrations lower in female than male patients and controls) implies that Hcy metabolism may not differ between diabetic patients and control subjects. Das et al. (1999) suggested that NIDDM may strongly promote oxidative stress and enhance CVD in patients who have coexistent hyperhomocysteinemia. Despite no significant variation of Cys and CysGly concentrations was observed in our study, the increase of oxidative stress is confirmed, for women, in diabetic patients with lower GSH than in controls (Sundaram et al. 1996) and with a GGT activity related to oxidative stress in type 2 diabetes (Perry et al. 1998). The relationship between GGT activities and its pro-oxidant effect has been demonstrated in vitro (Drozdz et al. 1998; Enoiu et al. 2000) and in clinical studies by the increase in lipid peroxidation (Pompella
1997; Perry et al. 1998). Our findings were in agreement with Sundaram et al. (1996) stressing to an increase in lipid peroxidation in patients with type 2 diabetes mellitus. Using the ferrous-oxidation of xylenol orange assay to determine lipid hydroperoxides, Nourooz-Zadeh et al. (1997) suggested that changes in oxidative stress were related to the underlying metabolic abnormalities in type 2 diabetes mellitus rather than to the appearance of complications. This is supported by the finding of raised LPO products in patients with impaired glucose tolerance, even before the onset of frank diabetes (Vijayalingam et al. 1996). In our study, a raised LPO was demonstrated in female diabetic patients with higher MDA concentrations than in controls. The higher level of oxidative stress in women might be because of their higher BMI levels. The average plasma concentrations of MDA measured in our healthy adults were similar to those found by Carbonneau et al. (1991), and higher values observed in diabetic patients were described by Langley et 
al. (1993) in ill subjects concerned by such oxidative stress related pathologies. Moreover, in healthy individuals, oxidative damage was reported to be more extensive in women than in men in a study performed by Block et al. (2002), whereas Ide et al. (2002) found enhanced oxidative stress in men compared to women.

The TAS should reflect the ability of an individual to resist oxidative stress. Low serum antioxidative activity in NIDDM may be related to an increased tendency to LPO. According to our results, there was no significant difference in serum TAS between diabetic patients and control subjects, which is in contrast to other reports showing a decreased antioxidative activity in diabetic patients (Ceriello et al. 1997; Maxwell et al. 1997) but in concordance with Leinonen et al. (1998). However, the relevance of the Randox-TAS ${ }^{\circledR}$ has been recently discussed in comparison with other "antioxidant assays", i.e., the oxygen radical absorbance capacity (ORAC) and the ferric reducing ability of plasma (FRAP) assays (Cao and Prior 1998): a low correlation was pointed out between TAS and the two other methods. Nevertheless, TAS is also an easier approach than specific methods such as hydroxylation of aspirin (generation of hydroxyl radical) already used in NIDDM (Ghiselli et al. 1992). Several studies have consistently demonstrated deficiency in individual antioxidants in NIDDM patients (Sundaram et al. 1996; Vijayalingam et al. 1996; Ceriello et al. 1997; Nourooz-Zadeh et al. 1997) with reduced concentrations of GSH, vitamin $\mathrm{C}$ and the antioxidant enzymes, i.e., superoxide dismutase and catalase, as well as a decrease in total radical trapping antioxidant parameter, suggesting a reduced total antioxidant defence. Overall, these studies assume that oxidative stress and impaired antioxidant defence is a feature of type 2 diabetes mellitus that is present early in the disease and may contribute to its progression and even to the development of complications.
In the present study, we have confirmed that type 2 diabetic women patients developed an oxidative stress by the decline in antioxidant defense including a lowered GSH (as a major antioxidant) level and an increased MDA (as a LPO product) concentration. These findings are of particular interest in view of the fact that women might be at a greater risk of diabetes than men. The increased oxidative damage that we have pointed out may therefore predispose to the development of CVD. Profiling the oxidative stress parameters status in such a pathology may contribute to protection from CVD in the female population.

\section{References}

Angelico, F., Del Ben, M., Giampaoli, S., Menotti, A., Ricci, G., Savocchi, P., Spitoni, M., Volpe, R. \& Urbinati, G.C. (1990) High prevalence of obesity in rural community of central Italy: The "Di.S.Co." project. In: World Data Book of Obesity, "6th International Congress on Obesity", edited by S. Baba \& P. Zimmet, Excerpta Medica, Amsterdam.

Araki, A., Sako, Y., Fukushima, Y., Matsumoto, M., Asada, T. \& Kita, T. (1989) Plasma sulfhydryl-containing amino acids in patients with cerebral infarction and in hypertensive subjects. Atherosclerosis, 79, 139-146.

Assmann, G., Carmena, R., Cullen, P., Fruchart, J.C., Jossa, F., Lewis, B., Mancini, M. \& Paoletti, R. (1999) Coronary heart disease, reducing the risk: a worldwide view. International Task Force for the Prevention of Coronary Heart Disease. Circulation, 100, 1930-1938.

Block, G., Dietrich, M., Norkus, E.P., Morrow, J.D., Hudes, M., Caan, B. \& Packer, L. (2002) Factors associated with oxidative stress in human populations. Am. J. Epidemiol., 156, 274-285.

Boemi, M., James, R.W., Romagnoli, E., Gerber, P., Pometta, D. \& Fumelli, P. (1993) Gender differences in a Type 2 (NIDDM) diabetic population. Diabetologia, 36, 29-233.

Boushey, C.J., Beresford, S.A., Omenn, G.S. \& Motulsky, A.G. (1995) A quantitative assessment of plasma homocysteine as a risk factor for vascular disease: probable benefits of increasing folic acid intakes. JAMA, 274, 1049-1057. 
Cao, G. \& Prior, R.L. (1998) Comparison of different analytical methods for assessing total antioxidant capacity of human serum. Clin. Chem., 44, 1309-1315.

Carbonneau, M.A., Peuchant, E., Sess, D., Canioni, P. \& Clerc, M. (1991) Free and bound malondialdehyde measured as thiobarbituric acid adduct by HPLC in serum and plasma. Clin. Chem., 37, 1423-1429.

Ceriello, A., Bortolotti, N., Falleti, E., Taboga, C., Tonutti, L., Crescentini, A., Motz, E., Lizzio, S., Russo, A. \& Bartoli, E. (1997) Total radical-trapping antioxidant parameter in NIDDM patients. Diabetes Care, 20, 194197.

Chico, A., Perez, A., Cordoba, A., Arcelus, R., Carreras, G., de Leiva, A., Gonzalez-Sastre, F. \& Blanco-Vaca, F. (1998) Plasma homocysteine is related to albumin excretion rate in patients with diabetes mellitus: a new link between diabetic nephropathy and cardiovascular disease. Diabetologia, 41, 684-693.

Das, S., Reynolds, T., Patnaik, A., Rais, N., Fink, L.M. \& Fonseca, V.A. (1999) Plasma homocysteine concentrations in Type II diabetic patients in India: relationship to body weight. J. Diabetes Complicat., 13, 200-203.

De Zwart, L.L., Meerman, J.H., Commandeur, J.N. \& Vermeulen, N.P. (1999) Biomarkers of free radical damage applications in experimental animals and in humans. Free. Radic. Biol. Med., 26, 202-226.

Diaz, J., Serrano, E., Acosta, F. \& Carbonell, L.F. (1998) Reference intervals for four biochemistry analytes in plasma for evaluating oxidative stress and lipid peroxidation in human plasma. Clin. Chem., 44, 2215-2217.

Drozdz, R., Parmentier, C., Hachad, H., Leroy, P., Siest, G. \& Wellman, M. (1998) $\gamma$ Glutamyltransferase dependent generation of reactive oxygen species from a glutathione/ transferrin system. Free Radic. Biol. Med., 25, 786-792.

Enoiu, M., Aberkane, H., Salazar, J.F., Leroy, P., Groffen, J., Siest, G. \& Wellman, M. (2000) Evidence for the pro-oxidant effect of gammaglutamyltranspeptidase-related enzyme. Free Radic. Biol. Med., 29, 825-833.

Garewal, H.S. (1997) Antioxidants and Disease Prevention. CRC Press Ltd., New York.

Ghiselli, A., Laurenti, O., De Mattia, G., Maiani, G. \& Ferro-Luzzi, A. (1992) Salicylate hydroxyla- tion as an early marker of oxidative stress in diabetic patients. Free Radic. Biol. Med., 13, 621-626.

Graham, I.M., Daly, L.E., Refsum, H.M., Robinson, K., Brattstrom, L.E., Ueland, P.M., Palma-Reis, R.J., Boers, G.H., Sheahan, R.G., Israelsson, B., Uiterwaal, C.S., Meleady, R., McMaster, D., Verhoef, P., Witteman, J., Rubba, P., Bellet, H., Wautrecht, J.C., de Valk, H. W., Sales Luis, A.C., Parrot-Rouland, F.M., Tan, K.S., Higgins, I., Garcon, D. \& Andria, G. (1997) Plasma homocysteine as a risk factor for vascular disease. The European Concerted Action Project. JAMA, 22, 1775-1781.

Hoogeveen, E.K., Kostense, P.J., Beks, P.J., Mackaay, A.J., Jakobs, C., Bouter, L.M., Heine, R.J. \& Stehouwer, C.D. (1998) Hyperhomocysteinemia is associated with an increased risk of cardiovascular disease, especially in non-insulin-dependent diabetes mellitus: a population based study. Arterioscler. Thromb. Vasc. Biol., 18, 133-138.

Ide, T., Tsutsui, H., Ohashi, N., Hayashidani, S., Suematsu, N., Tsuchihashi, M., Tamai, H. \& Takeshita, A. (2002) Greater oxidative stress in healthy young men compared with premenopausal women. Arterioscler. Thromb. Vasc. Biol., 22, 438-442.

Jacob, R.A. \& Burri, H.S. (1996) Oxidative damage and defense. Am. J. Clin. Nutr., 63, 985S990S.

Langley, S.C., Brown, R.K. \& Kelly, F.J. (1993) Reduced free-radical-trapping capacity and altered plasma antioxidant status in cystic fibrosis. Pediatr. Res., 33, 247-250.

Leinonen, J., Rantalaiho, V., Lehtimaki, T., Wirta, O., Pasternack, A. \& Alho, H. (1998) The association between the total antioxidant potential of plasma and the presence of coronary heart disease and renal dysfunction in patients with NIDDM. Free Radic. Res., 29, 273-281.

Mansoor, M.A., Bergmark, C., Svardal, A.M., Lфnning, P.E. \& Ueland, P.M. (1995) Redox status and protein binding of plasma homocysteine and other aminothiols in patients with early-onset peripheral vascular disease. Homocysteine and peripheral vascular disease. Arterioscler. Thromb. Vasc. Biol., 15, 232-240.

Maxwell, S.R., Thomason, H., Sandler, D., LeGuen, C., Baxter, M.A., Thorpe, G.H., 
Jones, A.F. \& Barnett, A.H. (1997) Poor glycaemic control is associated with reduced serum free radical scavenging (antioxidant) activity in non-insulin-dependent diabetes mellitus. Ann. Clin. Biochem., 34, 638-644.

Meister, A. \& Tate, S.S. (1976) Glutathione and related g-glutamyl compounds: biosynthesis and utilization. Annu. Rev. Biochem., 45, 609-616.

Miller, N.J., Rice-Evans, C., Davies, M.J., Gopinathan, V. \& Milner, A. (1993) A novel method for measuring antioxidant capacity and its application to monitoring the antioxidant status in premature neonates. Clin. Sci., 84, 407-412.

Munshi, M., Stone, A., Fink, L. \& Fonseca, V. (1996) Hyperhomocysteinemia following a methionine load in non-insulin dependent diabetes and microvascular disease. Metabolism, 45, 133-135.

Nourooz-Zadeh, J., Rahimi, A., Tajaddini-Sarmadi, J., Tritschler, H., Rosen, P., Halliwell, B. \& Betteridge, D.J. (1997) Relationships between plasma measures of oxidative stress and metabolic control in NIDDM. Diabetologia, 40, 647-653.

Perry, I.J., Wannamethee, S.G. \& Shaper, A.G. (1998) Prospective study of serum gammaglutamyltransferase and risk of NIDDM. Diabetes Care, 21, 732-737.

Pompella, A. (1997) Biochemistry and histochemistry of oxidant stress and lipid peroxidation. Int. J. Vitam. Nutr. Res., 67, 289-297.

Salazar, J.F., Schorr, H., Herrmann, W., Herbeth, B., Siest, G. \& Leroy, P. (1999) Measurement of thiols in human plasma using liquid chromatography with precolumn derivatization and fluorescence detection. J. Chromatogr. Sci., $37,469-476$.

Stamler, J.S., Osborne, J.A., Jaraki, O., Rabbani, L.E., Mullins, M., Singel, D. \& Loscalzo, J. (1993)
Adverse vascular effects of homocysteine are modulated by endothelium-derived relaxing factor and related oxides of nitrogen. J. Clin. Invest., 91, 308-318.

Stamler, J.S. \& Slivka, A. (1996) Biological chemistry of thiols in the vasculature and in vascular-related disease. Nutr. Rev., 54, 1-30.

Sundaram, R.K., Bhaskar, A., Vijayalingam, S., Viswanathan, M., Mohan, R. \& Shanmugasundaram, K.R. (1996) Antioxidant status an lipid peroxidation in type II diabetes mellitus with and without complications. Clin. Sci., 90, 255-260.

The Expert Committee on the Diagnosis and Classification of Diabetes Mellitus. Report of the Expert Committee on the Diagnosis and Classification of Diabetes Mellitus (2000) Diabetes Care, 23, S4-S19.

Ueland, P.M., Refsum, H. \& Brattsrom, L. (1992) Plasma homocysteine and cardiovascular disease. In: Atherosclerotic Cardiovascular Disease, Hemostasis, and Endothelial Function, edited by R.B. Jr., Francis, Marcel Dekker Inc., New York, pp. 183-236.

Verhoef, P., Stampfer, M.J., Buring, J.E., Gaziano, J.M., Allen, R.H., Stabler, S.P., Reynolds, R.D., Kok, F.J., Hennekens, C.H. \& Willett, W.C. (1996) Homocysteine metabolism and risk of myocardial infarction: relation with vitamins $\mathrm{B} 6, \mathrm{~B} 12$ and folate. $\mathrm{Am}$. J. Epidemiol., 143, 845-859.

Vijayalingam, S., Parthiban, A., Shanmugasundaram, K.R. \& Mohan, V. (1996) Abnormal antioxidant status in impaired glucose tolerance and non-insulin-dependent diabetes mellitus. Diabetic Med., 13, 715-719.

Young, I.S. \& Trimble, E.R. (1991) Measurement of malondialdehyde in plasma by high performance liquid chromatography with fluorimetric detection. Ann. Clin. Biochem., 28, 504-508. 